\title{
$\mathrm{Al}(\mathrm{i}-\mathrm{Bu})_{3}-\mathrm{NH}_{3}$ 系気相反応による AlN 微粉体の合成
}

\author{
槌田＼cjkstart潔・竹下幸俊・山根＼cjkstart昭*. 加藤 昭夫 \\ $\left(\begin{array}{c}\text { 九州大学 工学部 応用化学科 } \\ * \text { 東洋ストウファー・ケミカル (株) }\end{array}\right)$
}

\section{Preparation of AlN Powders by Vapor Phase Reaction of $\mathrm{Al}(\mathrm{i}-\mathrm{Bu})_{3}-\mathrm{NH}_{3}$ System}

\author{
Kiyoshi TSUCHIDA, Yukitoshi TAKESHITA, Akira YAMANE* and Akio KATO \\ $\left(\begin{array}{l}\text { Department of Applied Chemistry, Faculty of Engineering, Kyusyu University } \\ 6-10-1, \text { Hakozaki, Higashi-ku, Fukuoka-shi } 812 \\ * \text { Toyo Stauffer Chemical Co., Ltd. }\end{array}\right)$
}

Preparation of $\mathrm{AlN}$ powders by vapor phase reaction of $\mathrm{Al}(\mathrm{i}-\mathrm{Bu})_{3}-\mathrm{NH}_{3}$ system was studied by using a flow method. Mixing temperature of $\mathrm{Al}(\mathrm{i}-\mathrm{Bu})_{3}-\mathrm{H}_{2}$ and $\mathrm{NH}_{3}$ streams was $200^{\circ} \mathrm{C}$ and reaction temperatures were $600^{\circ}-1400^{\circ} \mathrm{C}$. AlN powders produced were not crystalline at low temperatures, but became slightly crystalline at high temperature. Particle size of AlN powders decreased with an increase of reaction temperature $\left(600^{\circ} \mathrm{C}: 0.034 \mu \mathrm{m}, 1100^{\circ} \mathrm{C}: 0.025 \mu \mathrm{m}, 1400^{\circ} \mathrm{C}: 0.017 \mu \mathrm{m}\right)$. The carbon content in $\mathrm{AlN}$ powders was minimum at around $1200^{\circ} \mathrm{C}$. Heat treatment of as-synthesized AlN powders in $\mathrm{H}_{2}-\mathrm{NH}_{3}$ $(10: 1 \mathrm{in} \mathrm{mol})$ at $1400^{\circ} \mathrm{C}$ for $2 \mathrm{~h}$ decreased impurity oxygen and carbon from 18.8 wt\% to 4.5 wt\% and from 1.2 wt $\%$ to 0.6 wt\% respectively. Crystallization of as-synthesized AlN powders by heat-treatment in the same atmosphere was appreciable above $1200^{\circ} \mathrm{C}$, and heat treatment at $1400^{\circ} \mathrm{C}$ gave well crystallized AlN powders. Heat-treated AlN powders having the average particle size of $0.03 \mu \mathrm{m}$ densified to $90 \%$ theoretical without sintering aid by firing at $2000^{\circ} \mathrm{C}$ for $1 \mathrm{~h}$ under $N$, of $10 \mathrm{~kg} / \mathrm{cm}^{2}$.

[Received May 28, 1987 ; Accepted August 25, 1987]

Key-words : AlN, Vapor phase reaction, Triisobutyl aluminum

\section{1. 緒 言}

窒化アルミニウム（以下 $\mathrm{AlN}$ と略す）は高い熱伝導 性と電気絶縁性を持ち, 熱膨張率は Si に近い值を示 す1).このため, 半導体実装用の新しい放熱基板等の新 しい電子材料として注目されている. 更に, AlN は原 料や, 焼結方法の選択により透光性のセラミックスとも なり,その点でも注目されている2).

$\mathrm{AlN}$ 粉体は金属アルミニウムの窒化法, アルミナ還 元法, 気相反応 (CVD) 法, プラズマ法, $\mathrm{AlCl}_{3} \cdot \mathrm{NH}_{3}$ や $\left(\mathrm{NH}_{4}\right)_{3} \mathrm{AlF}_{6}$ の熱分解等種々の方法で合成が試みられ ている3).

本研究では, 高純度で均一な $\mathrm{AlN}$ 微粉体を得ること を目的とし,トリイソブチルアルミニウム $\left(\mathrm{Al}(\mathrm{i}-\mathrm{Bu})_{3}\right)$ -アンモニア $\left(\mathrm{NH}_{3}\right)$ 系気相反応により $\mathrm{AlN}$ 微粉体を合 成し, 反応条件と生成粉体の粒子形状, 結晶性等との関 係について検討した.

\section{2. 実 験}

$\mathrm{H}_{2}$ (宇島酸水素製, $99.99 \%$ ), $\mathrm{N}_{2}$ (大阪酸素製, $99.99 \%$ ) は活性化銅力ラムを通して脱酸素を行った後, 液体窒素 トラップで脱水, 乾燥して使用した. トリイソブチルア ルミニウム $\left(\mathrm{Al}(\mathrm{i}-\mathrm{Bu})_{3}\right.$, 東洋ストウファー・ケミカル製, $97.1 \%), \mathrm{NH}_{3}$ （製鐵化学製，99.999\%）は市販品をそ
のまま用いた。

$\mathrm{AlN}$ の合成装置を図 1 に示す. $\mathrm{Al}(\mathrm{i}-\mathrm{Bu})_{3}$ (以下 $\mathrm{TiB}$ $\mathrm{AL}$ と略す) は $60^{\circ} \mathrm{C}$ に保持した蒸発器から $\mathrm{H}_{2}$ ガスを キャリアとして反応管に導入した，TiBAL の飽和率は 約 $40 \%$ であった. 導入した TiBAL は別に導入した $\mathrm{NH}_{3}$ ガスと混合, 反応させた. 反応条件を次に示す.

$$
\begin{array}{ll}
\text { 反応温度 } & 600^{\circ} \sim 1400^{\circ} \mathrm{C} \\
\mathrm{TiBAL}-\mathrm{NH}_{3} \text { 混合温度 } & 200^{\circ} \mathrm{C} \\
{[\mathrm{TiBAL}]:\left[\mathrm{NH}_{3}\right]:\left[\mathrm{H}_{2}\right]=} & 1: 100: 1000(\text { in mol) } \\
\text { ガス総流量 } & 1100 \mathrm{ml} / \mathrm{min}
\end{array}
$$

生成粉体は連結したフラスコで捕集した. 収率はフラス コ内と反応管内の生成粉体を合わせて 30 ～70\% であっ

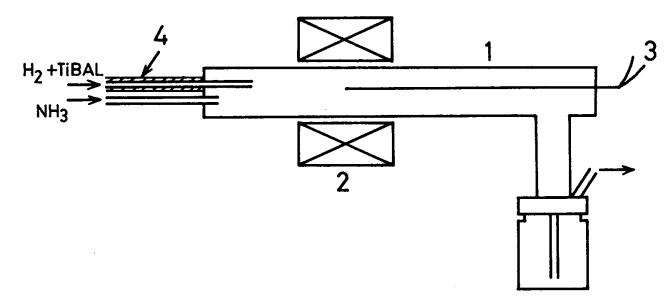

Fig. 1. Apparatus for synthesis of AlN powders. 1 : Alumina reaction tube $(\phi=22 \mathrm{~mm} \mathrm{I}$. D. ), 2 : Electric furnace,

3 : Thermocouple ( $\mathrm{Pt} / \mathrm{Rh}(6 \%)-\mathrm{Pt} / \mathrm{Rh}(30 \%))$, 4 : Ribbon heater 
た. 生成粉体を $\mathrm{N}_{2}$ 中と $\mathrm{H}_{2}-\mathrm{NH}_{3}$ 混合ガス中で熱処理し, 雲囲気及び熱処理温度の効果について調べた. 生成粉体, 熱処理粉体の同定，観察にはX 線回折計及び透過型電 子顕微鏡（TEM）を用いた. また，不純物炭素量は然 焼法により求め, 窒素及び酸素量は Leco, TC 136 に よって求めた.

熱処理粉体の焼結実験を行った．焼結は助剤無添加で 行った. 熱処理粉体を直径 $16 \mathrm{~mm}$ の金型にいれ, 一軸, $10 \mathrm{~kg} / \mathrm{cm}^{2}$ で成形し, 次いで $300 \mathrm{~kg} / \mathrm{cm}^{2}$ で 15 秒間ラバー プレスした。焼結は成形体を $\mathrm{BN}$ るつばに入れ $\mathrm{BN}$ 粉 で覆い, $\mathrm{N}_{2}\left(10 \mathrm{~kg} / \mathrm{cm}^{2}\right), 2000^{\circ} \mathrm{C}$ で 1 時間行った. 焼結 体破断面の観察には走査型電子顕微鏡 $(\mathrm{SEM})$ を用いた。

\section{3. 結果及び考察}

\section{1 生成粉体の形態}

図2に生成粉体の X 線回折図の反応温度による变化を 示す．生成粉体は反応温度が低温のとき非晶質であった

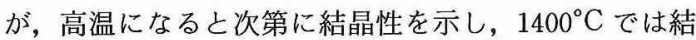
晶性はあまり良くないものの AIN の生成が確認できた。 生成粉体の TEM 写真を図 3 に示す. 生成粉体は球状

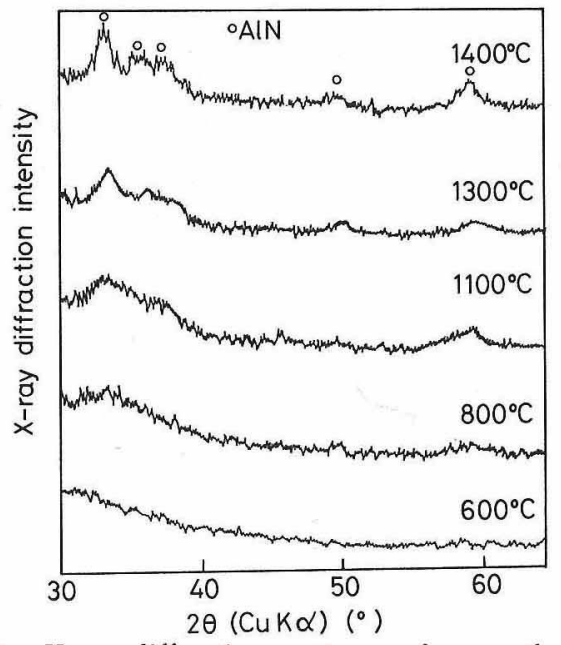

Fig. 2. X-ray diffraction patterns of as-synthesized powders.
粒子からなり粒径は比較的均一であった. 生成粉体の粒 子径は反応温度の上昇とともに減少した $\left(600^{\circ} \mathrm{C}\right.$ : $\left.0.034 \mu \mathrm{m}, 1100^{\circ} \mathrm{C}: 0.025 \mu \mathrm{m}, 1400^{\circ} \mathrm{C}: 0.017 \mu \mathrm{m}\right)$.

\section{2 生成粉体の炭素含有量}

生成粉体中の不純物炭素の含有量と反応温度との関係 を図 4 に示す. $1200^{\circ} \mathrm{C}$ 付近で炭素量は最小となった.

TiBAL は熱分解によって金属 $\mathrm{Al}$ と炭化水素に解離 する性質がある4). 実際，水素中， $300^{\circ} \mathrm{C}$ では金属 $\mathrm{Al}$ の析出が認められたが， $200^{\circ} \mathrm{C}$ では金属 $\mathrm{Al}$ の析出は起 こらなかった。したがって，本実験のように TiBAL と $\mathrm{NH}_{3}$ を $200^{\circ} \mathrm{C}$ で混合する場合，まず（1）式のように 両者の付加物が生成する．次にこれが反応管の高温部へ 移動したとき（2）式のように分解し AlN 粒子を生成 すると考えられる.

$$
\begin{aligned}
& \left(\mathrm{i}-\mathrm{C}_{4} \mathrm{H}_{9}\right)_{3} \mathrm{Al}+\mathrm{NH}_{3} \rightarrow\left(\mathrm{i}-\mathrm{C}_{4} \mathrm{H}_{9}\right)_{3} \mathrm{Al} \cdot \mathrm{NH}_{3} \\
& \left(\mathrm{i}-\mathrm{C}_{4} \mathrm{H}_{9}\right)_{3} \mathrm{Al} \cdot \mathrm{NH}_{3} \rightarrow \mathrm{AlN}+3\left(\mathrm{i}-\mathrm{C}_{4} \mathrm{H}_{10}\right)
\end{aligned}
$$

図 4 の結果は上記の AIN の生成過程から説明できる. 反応温度が $1200^{\circ} \mathrm{C}$ より低下すると炭素量が増加するの は付加物 $\left(\mathrm{i}-\mathrm{C}_{4} \mathrm{H}_{9}\right)_{3} \mathrm{Al} \cdot \mathrm{NH}_{3}$ の $\mathrm{AlN}$ への分解が不完全で 含炭素基が残存するためと考えられる. 一方高温側で炭 素量が増加するのは副生炭化水素の熱分解により遊離炭 素が析出するためと考えられる.

\section{3 生成粉体の熱処理}

生成粉体は炭素のほかに不純物として多量の酸素 (18.8 wt\%) を含んでいた.これは生成粉体が空気中で

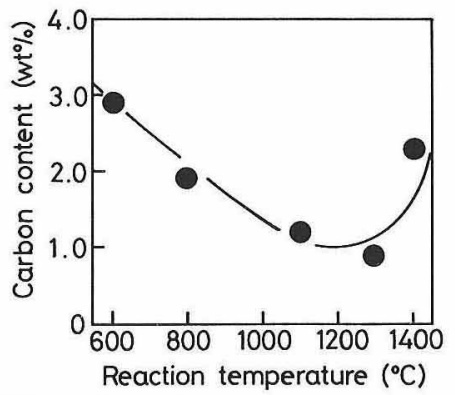

Fig.4. Effect of reaction temperature on carbon content of as-synthesized powders. (a)

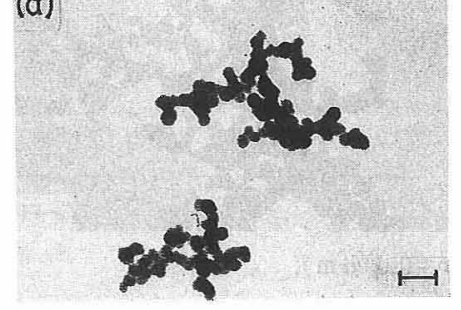

(b)

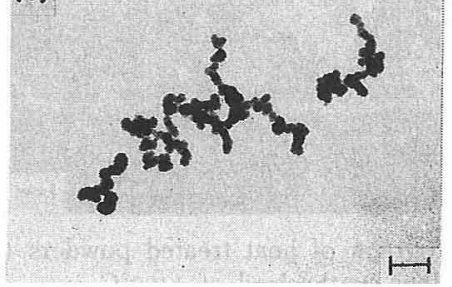

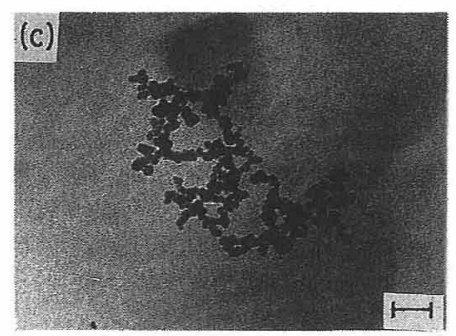

Fig. 3. TEM photograph of as-synthesized powders (bar=0.1 $\mu \mathrm{m})$.

Reaction temperature $\left({ }^{\circ} \mathrm{C}\right) \quad 600 \quad 1100 \quad 1400$

$\begin{array}{llll}\text { Average particle size }(\mu \mathrm{m}) & 0.034 & 0.025 & 0.017\end{array}$ 
の取扱い中に酸化されたためと考えられる．不純物炭素 及び酸素の除去を目的として $1400^{\circ} \mathrm{C}$ で熱処理を行っ た。熱処理には $1100^{\circ} \mathrm{C}$ で合成した粉体を用いた。 $\mathrm{N}_{2}$ 中 で熱処理したものには酸窒化物や， $\alpha$-アルミナの生成 が見られ，酸素が除去できなかった(図 5 ). 一方 $\mathrm{H}_{2}-$ $\mathrm{NH}_{3}(10: 1 \mathrm{in} \mathrm{mol})$ 混合ガス中で熱処理したものは, $\mathrm{X}$ 線回折では $\mathrm{AlN}$ 以外の X 線回折線は認められなかっ

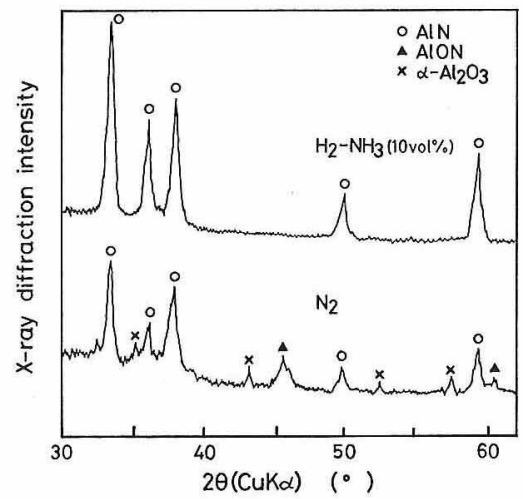

Fig. 5. Effect of heat-treatment atmosphere on impurities $\left(1400^{\circ} \mathrm{C}, 2 \mathrm{~h}\right)$.

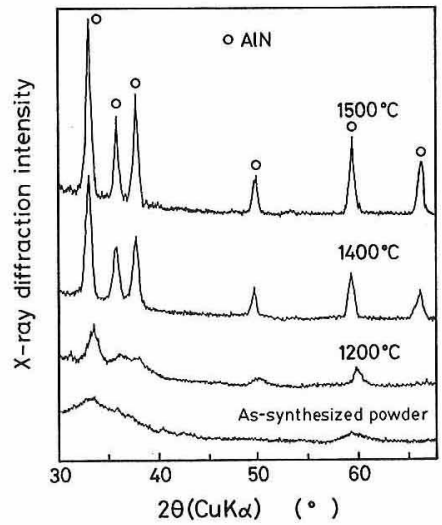

Fig.6. Effect of heat-treatment temperature on crystallization of as-synthesized powders.
た.この $\mathrm{H}_{2}-\mathrm{NH}_{3}$ 混合ガス中, $1400^{\circ} \mathrm{C}, 2$ 時間の熱処理 により $\mathrm{AlN}$ 中の不純物酸素量は $18.8 \mathrm{wt} \%$ 加ら 4.5 wt\% へ減少し，炭素量は $1.2 \mathrm{wt} \%$ から $0.6 \mathrm{wt} \%$ へと減 小した．雾囲気に還元性ガスを用いたことにより，酸素 は $\mathrm{H}_{2} \mathrm{O}$ ，炭素は $\mathrm{CH}_{4}$ として除去されると考えられる.

$1100^{\circ} \mathrm{C}$ で合成した粉体を $\mathrm{H}_{2}-\mathrm{NH}_{3}(10: 1 \mathrm{in} \mathrm{mol})$ 混 合ガス中で, 熱処理温度を変化させた場合の熱処理粉体 の X 線回折図の変化を図 6 に示す。 $1200^{\circ} \mathrm{C}$ ではあまり

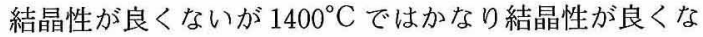
ることが分かった，図 7 に示すように，熱処理粉体は球 状粒子からなり一部合体はみられるが粒子径はかなり均 一であった。

\section{4 焼結}

本研究で合成した次の試料の焼結性を調べた。

$\begin{array}{ll}\text { 合成温度 } & 1100^{\circ} \mathrm{C} \\ \text { 熱処理温度 } & 1400^{\circ} \mathrm{C}\left(\mathrm{H}_{2}-\mathrm{NH}_{3} \text { 中, } 2 \mathrm{~h}\right) \\ \text { 平均粒径 } & 0.03 \mu \mathrm{m}\end{array}$

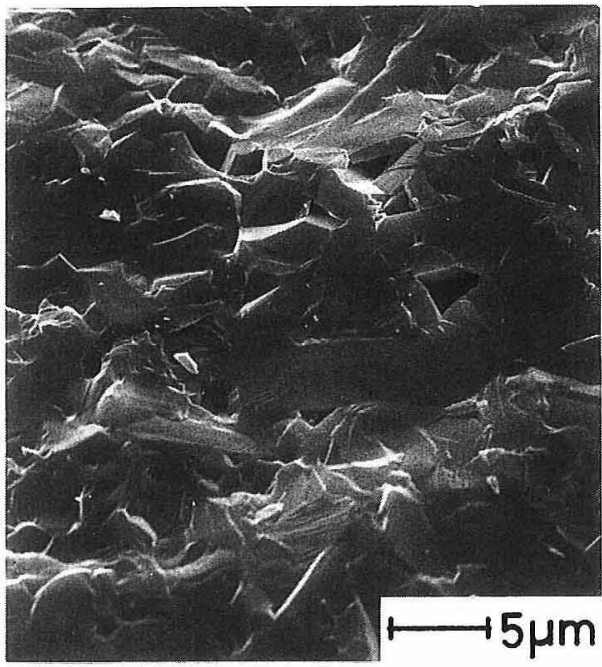

Fig. 8. SEM photograph of fracture surface of sintered body (Relative density : $90 \%$ ).
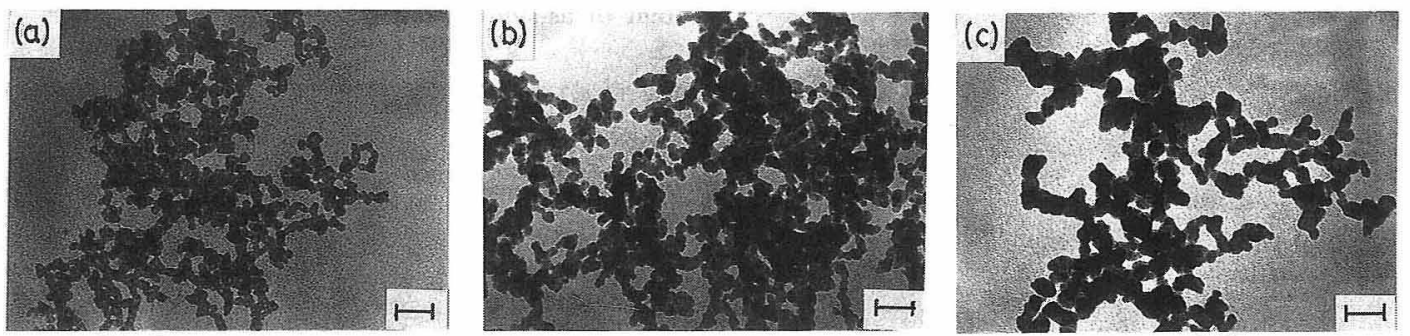

Fig. 7. TEM photograph of heat treated powders $(\mathrm{bar}=0.1 \mu \mathrm{m})$.

Sample : AlN powders synthesized at $1400^{\circ} \mathrm{C}$,

Heat treatment condition: $\mathrm{H}_{2}-\mathrm{NH}_{3}(10 \mathrm{vol} \%), 30 \mathrm{~min}$

$$
\text { (a) (b) (c) }
$$

Heat treatment temperature $\left({ }^{\circ} \mathrm{C}\right) \quad 1200 \quad 1400 \quad 1500$

$\begin{array}{llll}\text { Average particle size }(\mu \mathrm{m}) & 0.020 & 0.031 & 0.045\end{array}$ 
化学組成 $(w t \%) \quad N: 27.9,0: 4.5, C: 0.6$ 本研究の AlN 粉体からの焼結体の相対密度は $90 \%$ で あった。一方, 同一条件下での焼結で $\mathrm{Al}_{2} \mathrm{O}_{3}$ の還元窒化法 あるいは $\mathrm{Al}$ の窒化法で製造した市販品 AlN (1 3 $\mu \mathrm{m}$, $\left.\mathrm{O}_{2}: 1 \sim 2 \mathrm{wt} \%\right)$ からの焼結体の相対密度は $63 \sim 68 \%$ で， 本研究の超微粉体が焼結活性であることが分かった. 焼 結体破断面のSEM 写真を図 8 に示す. 粒子はかなり成 長しているが, 気孔は粒界にとどまっている.

\section{4. まとめ}

気相反応法によって粒径が小さく均一な AlN 超微粉
体を製造することができることが分かった。しかし，超 微粉体で表面積が大きいため表面酸化に基づくと考えら れる不純物酸素量が $4.5 \mathrm{wt} \%$ と多く，これを減少させ ることが今後の課題である.

\section{文 献}

1）篠崎和夫, 柘植章彦, セラミックス, 21, 1130-35(1986).

2) N. Kuramoto and H. Taniguchi, J. Mater. Sci. Lett., 3, 471-74 (1984).

3）倉元信行, セラミックス, 22, 29-34 (1987).

4) 大石克嘉, 谷 保雄, 第 33 回応用物理学関係連合講演会 予稿集, 715 (1986). 